\title{
2,4-D PESTICIDE ADSORPTION PERFORMANCE OF THE BIOMAGNETIC COMPOSITE
}

\author{
Gülbahar Akkaya Sayğılı \\ Department of Chemistry, Faculty of Education, Dicle University, 21280 Diyarbakır, Turkey
}

\begin{abstract}
In this study, a global waste was transformed a valuable and useful material by a comprehensive experimental setup. Lentil processing waste-based activated carbon with a high surface area of 1875 $\mathrm{m}^{2} / \mathrm{g}$ was synthesized by microwave-assisted $\mathrm{K}_{2} \mathrm{CO}_{3}$ chemical activation and then successfully converted into a ferrospinel composite. The synthesized ferrospinel composite was applied as an effective adsorbent material in the treatment of 2,4-dichlorphenoxyacetic acid herbicide bearing wastewater. Kinetic modeling of the experimental data obeyed the pseudo-second order model and the equilibrium studies well fitted to the Langmuir isotherm model. The maximum adsorption capacity of the ferrospinel composite towards 2,4-dichlorophenoxyacetic acid was $400 \mathrm{mg} / \mathrm{g}$ at $45{ }^{\circ} \mathrm{C}$. Thermodynamic studies showed the favorability and spontaneity of the adsorption process.
\end{abstract}

Key words: Lentil processing waste, microwave energy, magnetic composite, copper ferrite nanoparticles, herbicide adsorption

\section{Introduction}

2,4-Dichlorophenoxyacetic acid (2,4-D) is one of the water soluble herbicide that is widely used in agriculture sector. This most widely used herbicide selectively kills broadleaf weeds by leading uncontrolled growth in them. It can be detected in a lot of commercial grass herbicide mixes, and is widely applied as a weed-killer on cereal plants, grasslands, and fruit gardens. In addition this, over 1.500 herbicide products include 2,4-D as an active component [1]. To World Health Organization (WHO), it is moderately toxic to humans and animals and its maximum concentration is limited with $70 \mu \mathrm{g} / \mathrm{L}$ in drinking water by US Environmental Protection Agency (US EPA) [2]. Besides, 2,4-D has been categorized as carcinogen by US EPA and is doubted to be an endocrine disruptor and it causes sperms immobility, immune insufficiency disorders, kidney and respiratory problems [3]. Therefore, to remove 2,4-D from the environment is a very important issue to be solved. Many methods have been applied to remove 2,4-D from aquatic environment such as advance oxidation [4], photodegradation [5], chemical oxidation with ozone [6], coagulation [7] and adsorption. Of these methods, adsorption is the most preferred and applied due to its ease of operation, low-cost and environmentally friendly features.

\section{Materials and Method}

\subsection{Biowaste and reagents}

Lentil processing waste (LW) was suppled as crude biomaterial by a lentil processing factory at Batman in Turkey. $\mathrm{FeCl}_{3} \cdot 6 \mathrm{H}_{2} \mathrm{O}, \mathrm{CuCl}_{2}, \mathrm{~K}_{2} \mathrm{CO}_{3}, \mathrm{NaOH}, \mathrm{NaCl}, \mathrm{HCl}$ and 2,4-dichlorophenoxyacetic

*Corresponding author: Address: Department of Chemistry, Faculty of Education, Dicle University, 21280 Diyarbakır, Turkey. E-mail address: bahar.akkaya@dicle.edu.tr, Phone: +904122481000 
acid (2,4-D) were bought from Sigma-Aldrich Company.

\subsection{Fabrication of LPWAC by microwave-assisted chemical activation with $\mathrm{K}_{2} \mathrm{CO}_{3}$}

In this paper, prior to carbonization process conducted in a tubular furnace, the mixture of the LW and $\mathrm{K}_{2} \mathrm{CO}_{3}$ was treated with microwave energy (MW) in order to reduce the energy consumption for the chemical activation step. MW heating operations were carried out in a household type microwave furnace (Bosch, Model HMT84G451/36, $2450 \mathrm{MHz}$ ). The input power of the MW equipment was set at $900 \mathrm{~W}$ and the MW frequency used was $2.45 \mathrm{GHz}$. Crushed and sieved LPW samples were blended with $\mathrm{K}_{2} \mathrm{CO}_{3}$ to the wanted activating chemical/precursor ratio (weight of $\mathrm{K}_{2} \mathrm{CO}_{3}$ /weight of $\left.\mathrm{LW}\right)$ in Teflon beakers $(100 \mathrm{~mL})$. The $\mathrm{K}_{2} \mathrm{CO}_{3}$ impregnated samples were immediately subjected to MW treatment for 30 seconds. After that, the MW treated samples were subjected to carbonization.

\subsection{Fabrication of the ferrospinel composite}

$\mathrm{CuFe}_{2} \mathrm{O}_{4}$ spinel ferrite nanoparticles were loaded to the synthesized optimal activated carbon (LWAC) applying the co-precipitation method by the following procedure: $0.02 \mathrm{~mol} \mathrm{CuCl}_{2}$ and $0.04 \mathrm{~mol} \mathrm{FeCl}_{3} .6 \mathrm{H}_{2} \mathrm{O}$ were dissolved in $400 \mathrm{~mL}$ distilled water and thereafter $4.8 \mathrm{~g}$ of LWAC was added to the this mixture. With severe magnetic stirring, $5 \mathrm{M} \mathrm{NaOH}$ was put in drop by drop to increase the mixture $\mathrm{pH}$ to round 10 . This severe stirring was proceeded for 1 hour. Later on, the mixture was heated to $100{ }^{0} \mathrm{C}$ for 2 hours. Then, the prepared magnetic ferrospinel composite was washed with distilled water and separated from water by a simple magnetic procedure. Finally, the synthesized material (FLWAC) was dried at $110{ }^{\circ} \mathrm{C}$ in an oven for 24 hours.

\subsection{Herbicide batch adsorption experiments}

For the kinetic experiments, the data were obtained at 5-420 min time interval with $250 \mathrm{mg} / \mathrm{L}$ initial 2,4-D concentration. For the isotherm studies, 2,4-D initial concentrations ranged from 50 to 600 $\mathrm{mg} / \mathrm{L}$ and the temperatures were 298, $308 \mathrm{~K}, 318 \mathrm{~K}$, respectively. The amounts of 2,4-D adsorbed were measured by a UV-visible spectrophotometer (Perkin Elmer Lambda 25) at $282 \mathrm{~nm}$.

\section{Results and Discussion}

\subsection{Kinetic modeling of herbicide adsorption}

The 2,4-D adsorption rate on the FLWAC and the possible mechanism were analyzed by applying the experimental kinetic data to the pseudo first-order (PFO), pseudo second-order (PSO) and intraparticle diffusion models. The PFO model proposed by Lagergren [8] is expressed by the following linear equation:

$\log q_{e}=\log K_{F}+\frac{1}{n} \log C_{e}$

The PSO model proposed by Ho and McKay [9] is stated by this linear equation: 
$\frac{t}{q_{t}}=\frac{1}{k_{a d s, 2} q_{e}^{2}}+\frac{t}{q_{t}}$

where $\mathrm{t}$ is the time $(\mathrm{min}), \mathrm{q}_{\mathrm{e}}$ and $\mathrm{q}_{\mathrm{t}}(\mathrm{mg} / \mathrm{g})$ are the amounts of 2,4-D adsorbed at time $\mathrm{t}$ and equilibrium, respectively. $\mathrm{k}_{\mathrm{ads}, 1}\left(\mathrm{~min}^{-1}\right)$ is the PFO rate constant and $\mathrm{k}_{\mathrm{ads}, 2}(\mathrm{~g} /(\mathrm{mg} \cdot \mathrm{min}))$ is the PSO rate constant.

The kinetic parameters and related correlation coefficients $\left(\mathrm{R}^{2}\right)$ that calculated from the linear plots of the PFO and PSO models are reported in Table 1 . The PSO model has higher $\mathrm{R}^{2}$ and closer calculated $\mathrm{q}_{\mathrm{e}}$ values $\left(\mathrm{q}_{\mathrm{e}, \mathrm{cal}}\right)$ to the experimental $\mathrm{q}_{\mathrm{e}}$ values $\left(\mathrm{q}_{\mathrm{e}, \exp }\right)$ than the PFO model. Fitting the PSO model means that the adsorption of 2,4-D onto FLWAC adsorbent has a chemisorption ratecontrolling mechanism.

Table 1. Kinetic parameters of the 2,4-D adsorption by FLPWAC composite.

\begin{tabular}{lccccccccc}
\hline & \multicolumn{3}{c}{ PFO model } & \multicolumn{4}{c}{ PSO model } & \multicolumn{3}{c}{ W-M model } \\
$q_{e, \text { exp }}$ & $q_{e, \text { cal }}$ & $k_{a d s, 1}$ & $R^{2}$ & $q_{e, c a l}$ & $k_{a d s, 2}$ & $R^{2}$ & $k_{i d}$ & $R^{2}$ \\
\hline 149.74 & 112.85 & 0.011 & 0.9761 & 158.73 & $1.81 \times 10^{-4}$ & 0.9969 & 3.14 & 0.9953 \\
\hline
\end{tabular}

\subsection{Isotherm modeling and thermodynamics}

Langmuir [10] and Freundlich [11] isotherm models which are widely applied to describe adsorption isotherms were fitted to the equilibrium data of 2,4-D onto FLWAC. The linear forms of the Langmuir and Freundlich models are expressed by the following Eq. (3) and Eq. (4), respectively:

$\frac{C_{e}}{q_{e}}=\frac{1}{q_{m} b}+\frac{C_{e}}{q_{m}}$

$\log q_{e}=\log K_{F}+\frac{1}{n} \log C_{e}$

where $\mathrm{q}_{\mathrm{m}}(\mathrm{mg} / \mathrm{g})$ is the maximum adsorption capacity of the adsorbent, $\mathrm{b}(\mathrm{L} / \mathrm{mg})$ is the Langmuir parameter connected to the adsorption energy. $\mathrm{K}_{\mathrm{F}}$ and $\mathrm{n}$ are the Freundlich parameters reflects the adsorbent capacity and adsorption intensity, respectively. The isotherm parameters are given in Table 2.

Table 2. Isotherm parameters of the 2,4-D adsorption by FLPWAC composite.

\begin{tabular}{lcccccc}
\hline & \multicolumn{3}{c}{ Langmuir model } & \multicolumn{3}{c}{ Freundlich model } \\
$\mathrm{T}(\mathrm{K})$ & $q_{m}$ & $b$ & $R^{2}$ & $K_{F}$ & $1 / n$ & $R^{2}$ \\
\hline 298 & 263.16 & 0.0101 & 0.9900 & 14.79 & 0.46 & 0.9840 \\
308 & 370.37 & $2.93 \times 10^{-3}$ & 0.9858 & 4.94 & 0.63 & 0.9797 \\
318 & 400 & $3.71 \times 10^{-3}$ & 0.9940 & 7.93 & 0.56 & 0.9710 \\
\hline
\end{tabular}


It is observed from the table that, the correlation coefficients support the fact the 2,4-D removal by FLWAC followed the Langmuir model that explains the evenly distribution of the active adsorption sites on the FLWAC surface. The maximal adsorption capacity calculated from the Langmuir model was $400 \mathrm{mg} / \mathrm{g}$ at $318 \mathrm{~K}$ and this high 2,4-D adsorption capability of FLWAC could be attributed to the high surface area and porous structure of the synthesized AC.

The thermodynamic evaluation of the 2,4-D adsorption onto FLWAC was made using the thermodynamic parameters that calculated from the following equations:

In $K_{C}=-\frac{\Delta H^{0}}{R T}+\frac{\Delta S^{0}}{R}$

where $\mathrm{K}_{\mathrm{C}}$ is the distribution coefficient $\left(\mathrm{K}_{\mathrm{C}}=\mathrm{q}_{\mathrm{e}} / \mathrm{C}_{\mathrm{e}}\right)$ for the adsorption, $\mathrm{R}$ is the universal gas constant $(8,314 \mathrm{~J} / \mathrm{molK})$, and $\mathrm{T}$ is the absolute temperature $(\mathrm{K}) . \Delta \mathrm{H}^{0}$ and $\Delta \mathrm{S}^{0}$ are calculated from the slope and intercept of van't Hoff plots of In $\mathrm{K}_{\mathrm{C}}$ versus $1 / \mathrm{T}$ (Figure not shown). The positive $\Delta \mathrm{H}^{0}$ value $(30.99 \mathrm{~kJ} / \mathrm{mol})$ shows the endothermic adsorption of 2,4-D. The positive value of $\Delta \mathrm{S}^{0}$ $(104.76 \mathrm{~J} / \mathrm{molK})$ reveals that while 2,4-D adsorbed onto FLWAC, randomness increased on the surface due to the high affinity of the adsorbent surface to the 2,4-D. Besides, the negative $\Delta \mathrm{G}^{0}$ values $(-0.40,-0.82,-2.59 \mathrm{~kJ} / \mathrm{mol})$ at various temperatures thereby showing the feasibility and spontaneity of the 2,4-D elimination by FLWAC. In addition to this, more negative values with the rise of temperature point out that the adsorbed quantity of 2,4-D at equilibrium increases with rising temperature and more spontaneous at higher temperatures.

\section{Conclusions}

The magnetically separable FLWAC composite was used as a novel 2,4-D herbicide remover in wastewater treatment. The fitness of the isotherm data to the Langmuir model indicated the homogeneous dispersion of the active adsorption centers on the FLWAC surface. The adsorption kinetics of 2,4-D onto ferrospinel composite followed the PSO model. The spontaneous character of the 2,4-D adsorption was supported by negative $\Delta \mathrm{G}^{0}$ values which showed the absence of an energy hindrance for the adsorption process.

\section{Acknowledgement}

The author thanks to the Scientific Research Projects Unit of Dicle University (project code: ZGEF.16.014).

\section{References}

[1] Tomlin, C., The Pesticide Manual, 10th ed., Crop Protection Publications, Boca Raton, 1994.

[2] Zhu, L., Zhao, N., Tong, L., Lv, Y., Li, G., "Characterization and evaluation of surface modified materials based on porous biochar and its adsorption properties for 2,4dichlorophenoxyacetic acid”, Chemosphere, Vol.210, pp.734-744, 2018.

[3] Spaltro, A., Pila, M., Simonetti, S., Aluarez-Torrellas, S., Rodriguez, J.G., Ruiz, D., Company, A.D., Juan, A., Allegretti, P., "Adsorption and removal of phenoxy acetic herbicides from water by using commercial activated carbons: experimental and computational studies", Journal of Contaminant Hydrology, Vol.218, pp.84-93, 2018. 
[4] Chen, H., Zhang, Z., Yang, Z., Yang, Q., Li, B., Bai, Z., "Heterogeneous fenton-like catalytic degradation of 2,4-dichlorophenoxyacetic acid in water with FeS", Chemical Engineering Journal, Vol.273, pp.481-489, 2015.

[5] Tsogas, G.Z., Giokas, D.L., Nikolakopoulos, P.G., Vlessidis, A.G., Evmiridis, N.P., "Determination of the pesticide carbaryl and its photodegradation kinetics in natural waters by flow injection-direct chemiluminescense detection", Analytica Chemica Acta, Vol.573, pp.354-359, 2006.

[6] Broseus, R., Vincent, S., Aboulfadl, K., Daneshvar, A., Sauve, S., Barbeau, B., Prevost, M., "Ozone oxidation of pharmaceuticals, endocrine disruptors and pesticides during drinking water treatment", Water Research, Vol.43, pp.4707-4717, 2009.

[7] Ormad, M.P., Miguel, N., Claver, A., Matesanz, J.M., Ovelleiro, J.L., "Pesticides removal in the process of drinking water production", Chemosphere, Vol.70, pp.97-106, 2008.

[8] Lagergren, S., "About the theory of so-called adsorption of soluble substances" Kunglia Svenska Vetensk Handl. Vol.24, pp.1-39, 1898.

[9] Ho, Y.S., McKay, G., "Sorption of dye from aqueous solution by peat", Chemical Engineering Journal, Vol.70, pp.115-124, 1998.

[10] Langmuir, I., "The adsorption of gases on plane surfaces of glass, mica and platinum", Journal of American Chemical Society, Vol.40, pp.1361-1403, 1918.

[11] Freundlich, H., "On the adsorption in solutions", Journal of Physical Chemistry, Vol.57, pp.385-470, 1906. 